5. Cottin V, Nunes $\mathrm{H}$, Mouthon $\mathrm{L}$, et al. Combined pulmonary fibrosis and emphysema syndrome in connective tissue disease. Arthritis Rheum 2010;63:295-304.

\section{Influence of respiratory variables on the on-line detection of exhaled trace gases by PTR-MS}

\section{Background}

Modern gas analysis techniques permit real time and on-line quantification of multiple volatile trace gases within a single exhalation. However, the influence of various respiratory manoeuvres affecting exhalation flow and the kinetics of metabolite release to the gas-phase remain largely unknown.

\section{Methods}

We examined variation in the concentrations of selected trace gases over a range of expiratory flows $(50 ; 100 ; 250 \mathrm{ml} / \mathrm{s})$ and after 30 second periods of breathold and paced hyperventilation. On-line measurement of breath samples from healthy volunteers $(n=10)$ was performed by proton transfer mass spectrometry.

\section{Results}

Exhaled acetone increased with higher expiratory flow rate $(805,838,898 \mathrm{ppb}, \mathrm{p}=0.02)$. Levels of methanol (206 vs $179 \mathrm{ppb}, \mathrm{p}<0.01$ ) acetaldehyde ( 26 vs $22 \mathrm{ppb}, \mathrm{p}<0.01$ ), ethanol (410 vs $208 \mathrm{ppb}, \mathrm{p}=0.01$ ) and dimethyl sulphide $(113$ vs 103 ncps, $p<0.01)$ fell significantly following 30 s hyperventilation. After 30 second breathold levels of methanol (206 vs $217 \mathrm{ppb}, \mathrm{p}=0.02$ ), acetone (805 vs $869 \mathrm{ppb}, \mathrm{p}<0.01$ ), isoprene (348 vs $390 \mathrm{ppb}$, $p=0.02)$ and dimethyl sulphide (113 vs 136 ncps, $p=0.02$ ) increased significantly. Variation in respiratory parameters did not significantly alters the level of acetonitrile, propanol and butyric acid within the breath of healthy subjects.

\section{Conclusions}

These findings demonstrate that respiratory manoeuvres significantly influence the measured concentration of a number of exhaled VOCs that are of potential importance within the clinical setting. Our results support the adoption of standardised practices for breath gas analysis by on-line and real time mass spectrometry methods.

Analysis of volatile trace gases within exhaled breath, for the purpose of non-invasive disease detection and monitoring, is a rapidly emerging field of research. ${ }^{12}$ Recent technological developments such as proton transfer reaction-mass spectrometry (PTRMS) have allowed on-line and real-time detection of multiple trace gases in breath, leading to novel discoveries in cancer, infectious disease and metabolism. ${ }^{2} 3$

One of the greatest lessons on clinical applicability of breath analysis has been the recognition that multiple physiological variables can influence the quantification of exhaled nitric oxide (NO), necessitating international consensus guidelines for its standardised measurement. ${ }^{4}$ There remains however limited experimental evidence defining the impact of confounding factors which may influence the quantification of other exhaled volatile trace gases. ${ }^{5}$ Herein we present the finding of a study investigating the influence of respiratory variables on the on-line detection and quantification of a judiciously selected and potentially clinically relevant panel of expiratory trace gases.

We examined the variation in the concentrations of selected trace gases (methanol, acetaldehyde, ethanol, acetone, isoprene, acetonitrile, propanol, dimethyl sulphide and butyric acid) over a range of expiratory flows $(50,100,250 \mathrm{ml} / \mathrm{s})$ and after the 30 -s periods of breath hold and paced hyperventilation. These volatiles were compared to exhaled $\mathrm{NO}$ and carbon dioxide. On-line measurement of breath samples from healthy volunteers $(n=10)$ was performed by combining PTR-MS (Ionimed
Analytik $\mathrm{GmbH}$, Innsbruck, Austria) with the LR2500 multiple-gas analyser (Logan Research Ltd, Rochester, UK). Quantification of trace gases by PTR-MS was achieved by calibration experiments using accurately known gas standards and a purpose built gas calibration unit (Ionimed). (Further details of methodology are provided as supplementary digital content).

In contrast to $\mathrm{NO}$, exhibiting an inverse relationship with expiratory flow rate, exhaled acetone increased with higher flows (805 vs 838, $898 \mathrm{ppb}, \mathrm{p}=0.02$ ) (figure 1). After a 30 -s breath hold, levels of acetone (805 vs 869 ppb, $\mathrm{p}<0.01)$, methanol (206 vs $217 \mathrm{ppb}, \mathrm{p}=0.02$ ), isoprene (348 vs $390 \mathrm{ppb}$, $\mathrm{p}=0.02$ ) and dimethyl sulphide (113 vs 136 ncps, $p=0.02$ ) increased significantly. Levels of methanol (206 vs $179 \mathrm{ppb}, \mathrm{p}<0.01$ ), dimethyl sulphide (113 vs 103 ncps, $p<0.01$ ), acetaldehyde (26 vs $22 \mathrm{ppb}, \mathrm{p}<0.01$ ) and ethanol (410 vs $208 \mathrm{ppb}, \mathrm{p}=0.01)$ fell significantly following the 30-s hyperventilation (figure 1). Variation in respiratory parameters did not significantly alter the levels of acetonitrile, propanol and butyric acid (table 2 in online supplement).

This work constitutes the first concerted attempt to discern the effect of ventilatory variables on breath analysis by an on-line
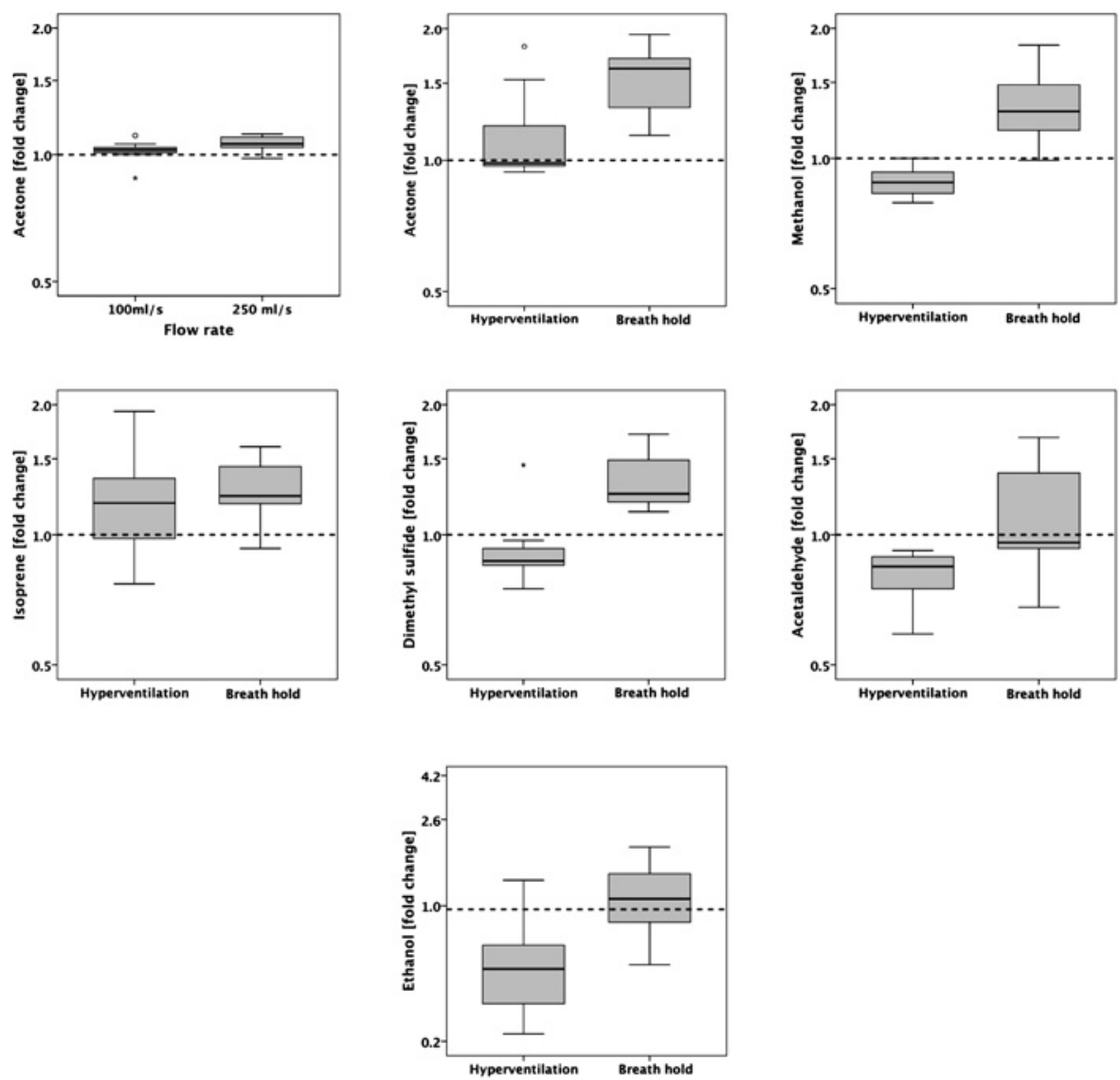

Figure 1 Influence of respiratory physiological variables on the concentrations of selected trace gases measured within the exhaled breath of healthy volunteers. Trace gas level are presented as the ratio of the difference in breath manoeuvres versus their respective control breath measures at a flow rate of $50 \mathrm{ml} / \mathrm{s}$. 
MS-based analytical technique. The principal findings of this study are (i) PTR-MS evidence for the flow dependency of exhaled acetone; (ii) changing minute ventilation can both increase and decrease the concentrations of selected exhaled trace gases; and (iii) concentrations of certain volatiles were not significantly altered by respiratory manoeuvres in healthy volunteers.

These preliminary observations may have important implications regarding the standardisation requirement for measuring and reporting the concentrations of exhaled trace gases in the future. Further larger studies both in healthy and diseased subjects are necessary to expand on these observations and to provide mechanistic insights into exchange kinetics of affected volatiles. Such studies may help to further define the exact role of on-line MS technologies in non-invasive diagnosis and monitoring pulmonary and systemic diseases.

\section{Piers R Boshier, ${ }^{1}$ Oliver H Priest, ${ }^{1}$ George B Hanna,' Nandor Marczin ${ }^{2,3}$}

${ }^{1}$ Department of Surgery and Cancer, Imperial College London, St Mary's Hospital, London, UK; '2Department of Surgery and Cancer, Section of Anaesthetics, Pain Medicine and Intensive Care, Imperial College London, Chelsea and Westminster Hospital, London, UK; ${ }^{3}$ Department of Anaesthetics, Harefield Hospital, The Royal Brompton and Harefield NHS Foundation Trust, Harefield, Middlesex, UK

Correspondence to Dr Nandor Marczin, Department of Surgery and Cancer, Section of Anaesthetics, Pain Medicine and Intensive Care, Imperial College London, Chelsea and Westminster Hospital, London SW10 9NH, UK; n.marczin@imperial.ac.uk

- An additional table is published online only. To view this file please visit the journal online (http://thorax.bmj.com).

\section{Competing interests None.}

Ethics approval This study was conducted with the approval of the Riverside Research Ethics Committee (project reference number: 08/H0706/134).

Provenance and peer review Not commissioned; externally peer reviewed.

Accepted 9 February 2011

Published Online First 7 April 2011

Thorax 2011;66:919-920.

doi:10.1136/thx.2011.161208

\section{REFERENCES}

Kharitonov SA, Barnes PJ. Exhaled biomarkers. Chest 2006;130:1541-6.

2. Amann A, Smith D, eds. Breath Analysis for Clinical Diagnosis and Therapeutic Monitoring. Singapore: World Scientific, 2005.

3. Lindinger W, Hansel A, Jordan A. On-line monitoring of volatile organic compounds at pptv levels by means of proton-transfer-reaction mass spectrometry (PTR-MS)-medical applications, food control and environmental research. Int J Mass Spectrom 1998:173:191-241.

4. American Thoracic Society; European Respiratory Society. ATS/ERS recommendations for standardized procedures for the online and offline measurement of exhaled lower respiratory nitric oxide and nasal nitric oxide, 2005. Am J Respir Crit Care Med 2005;171:912-30.
5. Larstad MA, Toren K, Bake B, et al. Determination of ethane, pentane and isoprene in exhaled air: effects of breath-holding, flow rate and purified air. Acta Physiol (Oxf) 2007;189:87-98.

\section{Association of IgG4-related disease and sarcoidosis}

Autoimmune pancreatitis (AIP) is a syndrome characterised by an enlarged pancreas with an irregular narrowing of the main pancreatic duct, a high serum IgG4 concentration and IgG4-positive plasma cell tissue infiltration.
A wide variety of lesions have been associated with AIP, including pulmonary lesions. ${ }^{1}$ Consequently, the terms "IgG4-positive multi-organ lymphoproliferative syndrome (IgG4+ MOLPS)" seem more appropriate. ${ }^{2}$

To our knowledge, sarcoidosis has never been reported in association with AIP. We report the case of an association of AIP with sarcoidosis in an elderly woman.

An 80-year-old woman presented with a 1-year history of chronic diarrhoea and a weight loss of $12 \mathrm{~kg}$ during the previous 6 months. Physical examination was normal. Chest and abdominal CT scan disclosed an increased volume of the pancreas, coeliac and
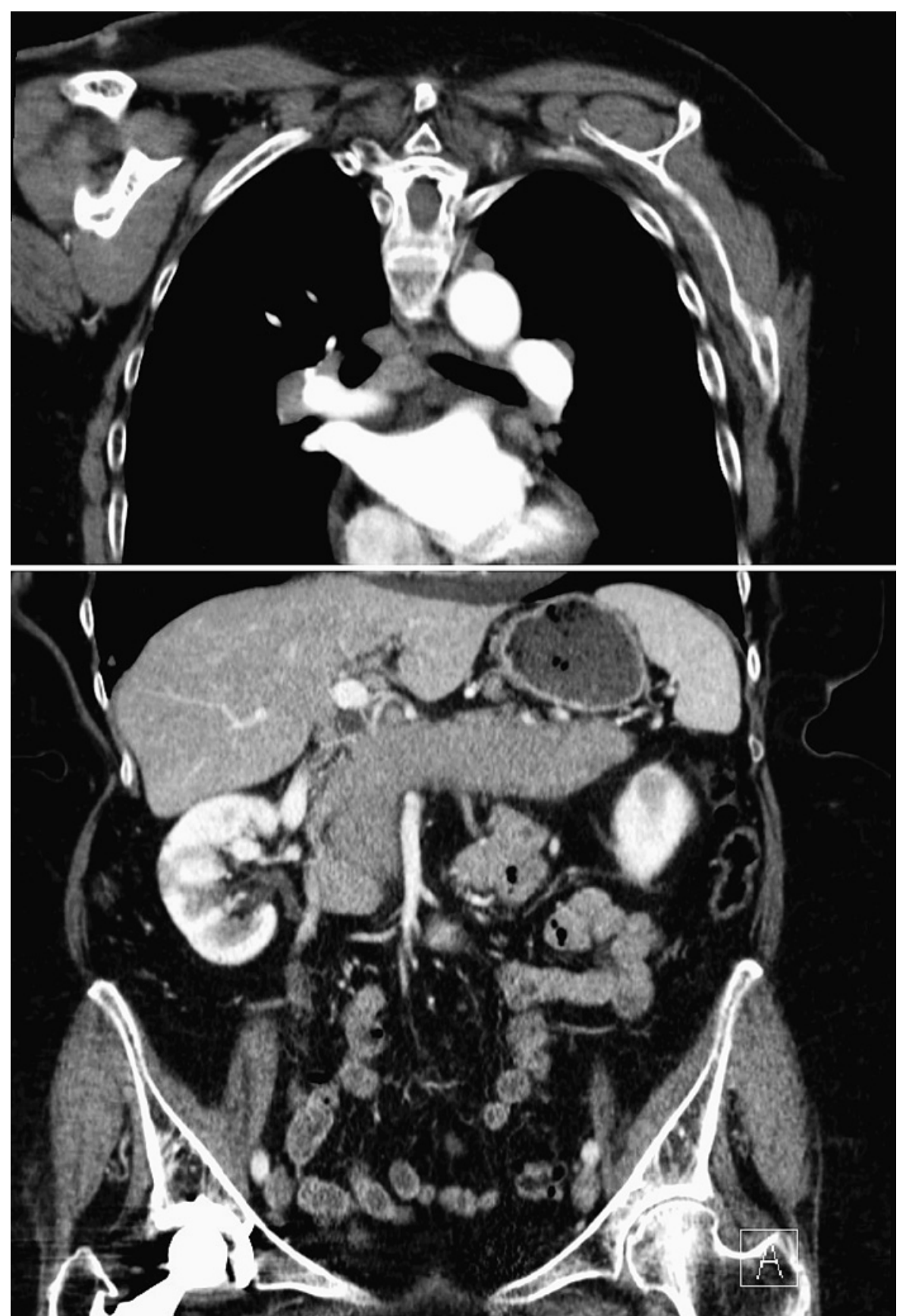

Figure 1 Contrast-enhanced coronal reformatted CT view: hilar and mediastinal adenomegaly, diffuse homogeneous hypoattenuating enlargement of the pancreas with minimal peripancreatic stranding. 